\title{
The Influence of Underlying Stresses from Environmental Hazards on Resilience in Bangladesh: A System View
}

\author{
Philip Lake ${ }^{1} \cdot$ Richard Fenner ${ }^{2}$
}

Published online: 17 October 2019

(C) The Author(s) 2019

\begin{abstract}
Bangladesh is one of the countries most vulnerable to climate change, while its people also suffer from a range of environmental hazards linked to the growing prevalence of non-communicable diseases. These diseases are responsible for increasing morbidity and mortality and lead to other stresses within the population. Such stresses create continuous impacts on the health and well-being of the population, compounding their vulnerability and inhibiting their capacity to cope with frequent event-related shocks, such as floods and drought. A systems approach is taken to examine four important environmental hazards in Bangladesh-arsenic contamination of drinking water, arsenic transmission through the food chain, indoor air quality, and air pollution. A review of these hazards is presented in a conceptual framework that links human well-being with the key system components of infrastructure, institutions, knowledge, and behavior. This reveals key underlying factors between the hazards and uncovers system structures that can lead to more effective hazard mitigation, and the establishment of strategic intervention points. The article concludes that elimination of these continuous stresses will only come about through the culmination of multiple interventions over time, undertaken in an iterative manner that builds on the continual advancement of hazard understanding. The role of individual behaviors, together with factors such as risk awareness and perception of the hazards, has been identified as crucial for
\end{abstract}

Richard Fenner

raf37@cam.ac.uk

Building Sustainability Group, Arup, London W1T 4BQ, UK

2 Centre for Sustainable Development, Engineering Department, Cambridge University, Cambridge CB2 1TN, UK achieving successful mitigation solutions. Improved knowledge of the hazards, public awareness, and government accountability are focus points to reduce population exposure and enhance response capacity.

Keywords Air pollution - Arsenic

contamination - Bangladesh · Drinking water

contamination · Environmental hazards · Resilience

\section{Introduction}

Over the last decade, there has been a substantial amount of research on, and investment in, disaster risk reduction and developing the concept of urban resilience (Hernantes et al. 2019; Kabir, Sato, et al. 2018). A focus has been on mitigating the "shocks" of natural hazards and disasters (Birkmann and Peduzzi 2007; Cai et al. 2018; Zobel and Baghersad 2018), and on understanding how to ensure that our socio-technical systems respond, adapt, and recover from natural and anthropogenic hazards (Moghim and Garna 2019). However, in order to build climate-resilient societies, the human capacity of vulnerable populations to cope with long-term stressors arising from environmental hazards must also be enhanced (Akter and Mallick 2013).

The development of resilience requires the mitigation or elimination of ongoing vulnerabilities, including exposure to constant environmental stresses that damage the wellbeing and health of the population. Whereas shocks denote discrete event-based hazards, stresses refer to continuous perils and are derived from an ongoing situational context. It is important to think of not only how to prepare for, and recover from, a significant event in order to resume normal service, but to address the continuous degrading stresses that detract from these efforts. Figure 1 illustrates that, 
Fig. 1 Closing the resilience gap in vulnerable populations
Reducing the impact of shocks and increasing the well-being of the population closes the vulnerability gap

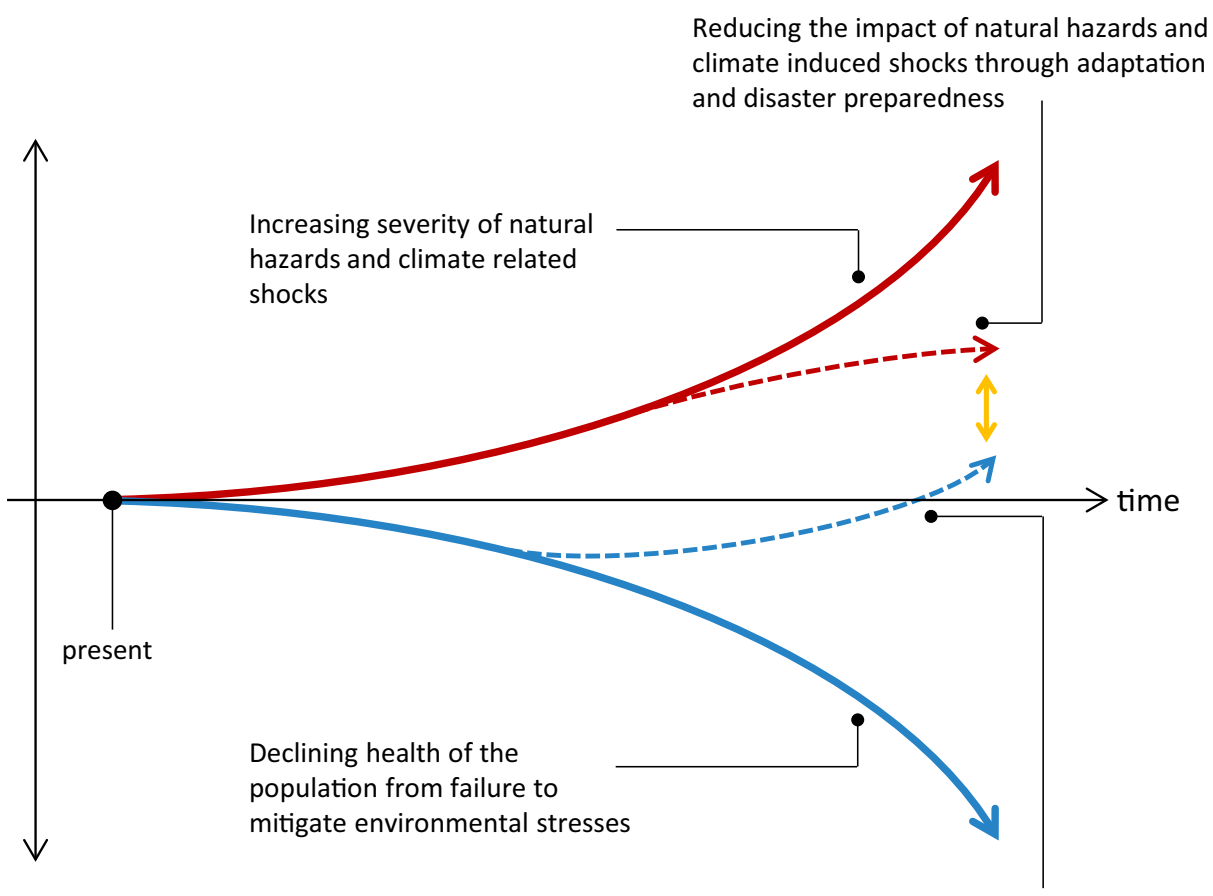

Improving the health, well-being and overall capacity of the population through mitigation of the ongoing hazard

Severity and frequency of climate change related shocks

Health / capacity of population
Minimizing this gap is key to enhancing overall resilience with the mitigation of climate shocks and the reduction of vulnerability to stresses, overall resilience can be improved and that it is not sufficient to respond to the shocks alone.

Bangladesh is subject to events such as floods, droughts, and tropical cyclones that produce "shocks." The country also suffers from continuous "stresses," for example from arsenic contamination and poor air quality (Toufique and Islam 2014). Tens of millions of people in Bangladesh are at extreme risk from these environmental hazards and continued exposure leads to suffering, loss of potential, premature death, and the onset of debilitating non-communicable diseases (the leading cause of death globally) (Murcott 2012; WHO 2017a).

The resultant growing burden of degraded well-being is not only hampering development but reducing the population's response capacity - that is, the system's ability to react to a shock - and hence overall resilience (Akter and Mallick 2013). The impact of these shocks is felt especially by the poorest segments of the population, and their vulnerability is compounded by the number of environmental hazards prevalent in Bangladesh (Ayeb-Karlsson et al. 2016). Slow-onset natural hazards have driven migration from northwest rural Bangladesh (Kabir, Serrao-Neumann, et al. 2018; Rahman et al. 2018) as the most hazard-prone riparian rural households are unable to cope with the impacts of climate change and associated environmental hazards due to a lack of adaptation options along with their poor socioeconomic conditions (Alam et al. 2018).

This article uses a qualitative visual framework, based on a simplified systems approach-originally presented by da Silva et al. (2012)_to review current mitigation approaches to stresses in Bangladesh and identifies which system components hold the greatest opportunity to improve well-being, reduce vulnerability, and promote resilience. The existing barriers to the effective mitigation 
and prevention of continuous environmental hazards in Bangladesh are also identified.

\section{Bangladesh Vulnerability}

Bangladesh is one of the most densely populated countries in the world with a land area of $147,600 \mathrm{~km}^{2}$ and a population of 161.36 million (World Bank 2018). The country ranks sixth on the 2018 Global Climate Risk Index and third in terms of the number of total events from 1997 to 2016 (Eckstein et al. 2018). It faces a multitude of environmental hazards due to its physical geography (Khan 2013) and is at specific risk due to its exposure to sea-level rise, cyclones, food insecurity, and exacerbation of health issues through climate change (ICCCAD 2014). Dhaka, the capital city of Bangladesh, is one of the largest cities in the world, with 14.65 million people (Shell Global 2019) and a population density of 44,500 people $/ \mathrm{km}^{2}$, resulting in significant pressures (Brodie 2017).

In recent decades Bangladesh has been in the midst of a rapid transition and has made developmental progress in transforming the economy from agriculture-based to industry oriented, with significant investment in infrastructure and the penetration of micro-finance institutions into rural communities, having faced severe challenges, such as poverty, weak governance, political instability, and exposure to natural hazards (Sawada et al. 2017). In the United Nations Human Development Index 2018 update, the country was ranked 136th out of the 189 countries assessed, with a score of 0.608 (UNDP 2018). This compares with an HDI of 0.387 in 1990 and 0.477 in 2000 confirming this steady progress.

The rise of chronic diseases related to environmental hazards has created major societal problems, limiting economic advancement and reducing human welfare. In $2015,67 \%$ of deaths in Bangladesh were attributable to non-communicable diseases (WHO 2017a) and their prevalence is an increasing burden on the country (Karar et al. 2009; Mirelman et al. 2016). This situation is unsustainable, especially as Bangladesh's population ages and continues to increase. Bangladesh has one of the world's worst environmental and lifestyle risk profiles, characterized by severe air and water pollution, nutritional disorders, and risk behaviors associated with a "Western" lifestyle, such as unhealthy diets and physical inactivity. These social, environmental, and behavioral risk factors share antecedents and causes, amplify each other's effects, and depend on one another in complex (and non-obvious) ways. Importantly, they can also exert different effects in varying contexts such as across rural, urban, and slum settings.
The range of environmental hazards that Bangladesh faces is summarized in Fig. 2 (Smith 2013). The long-term stresses are shown in bold; they impact the enduring wellbeing of the population and their capacity to respond to climate change vulnerabilities.

\section{Methodological Approach}

The following analysis adopts a systems thinking mindset to analyze the current efforts to reduce the exposure of Bangladesh's population to a range of environmental hazards linked to arsenic contamination and air pollution. A framework has been adapted based on the da Silva et al. (2012) approach to conceptualizing socio-technical systems in a way that does not require complex modeling and can be readily understood by city planners and key decision makers. This conceptual framework is shown in Fig. 3 and expresses the link between well-being and the hazards that affect human well-being by identifying various "sociotechnical networks" that are components of the wider system. Resilience can therefore be examined indirectly by the changing performance of these system components in response to shocks and stresses.

The framework captures both (physical) and intangible (social/psychological) factors-for example, tube-well infrastructure and knowledge of potential corruption. Three of the framework's elements-infrastructure, institutions, and knowledge - are drawn from the da Silva et al. (2012) classification. To these a fourth element-behavior-has been added for this analysis.

- Infrastructure-The infrastructure networks include the physical and technological solutions, approaches, and assets relevant to each ongoing stress. Infrastructure enables the fundamental services and access to resources on which society relies.

- Institutions-The institutional networks are the establishments that have control over rules, decision making, and financial capital that support human interaction. Not only do they include the governance systems ranging from national to community level, but also private firms and nongovernmental organizations (NGOs) that operate collaboratively or in isolation.

- Knowledge-The knowledge network is formed by the sociocultural systems and structures that facilitate access to information. This includes educational organizations such as universities that disseminate academic research, professional networks, and less formal routes to information such as mass media, social media, and community gatherings. The access to and flow of information and knowledge is crucial to resilience as it is what facilitates learning and change. 
Fig. 2 Environmental hazards faced by Bangladesh-longterm stresses in bold. Source Modified after Smith (2013)

\begin{tabular}{|c|c|c|c|c|c|c|}
\hline & \multicolumn{4}{|c|}{ Natural } & \multirow{2}{*}{\multicolumn{2}{|c|}{$\begin{array}{l}\text { Anthropogenic } \\
\text { Technological }\end{array}$}} \\
\hline & Hydrologic & Atmospheric & Biologic & Geologic & & \\
\hline \multirow[t]{2}{*}{ Stresses } & Drought & & & $\begin{array}{l}\text { Arsenic water } \\
\text { contamination }\end{array}$ & $\begin{array}{l}\text { Indoor air quality } \\
\text { pollution }\end{array}$ & $\begin{array}{l}\text { Arsenic contamination } \\
\text { of the food chain }\end{array}$ \\
\hline & River floods & Tornadoes & $\begin{array}{l}\text { Epidemic } \\
\text { diseases }\end{array}$ & Landslides & Transport accidents & Hazardous material \\
\hline Shocks & $\begin{array}{l}\text { Coastal floods } \\
\text { Drought }\end{array}$ & $\begin{array}{l}\text { Tropical } \\
\text { cyclones }\end{array}$ & & Earthquakes & Industrial failures & $\begin{array}{l}\text { Unsafe built } \\
\text { environment }\end{array}$ \\
\hline
\end{tabular}

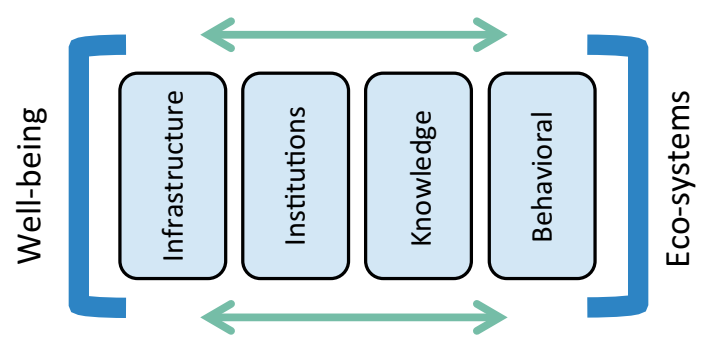

Fig. 3 System interactions between human well-being and environmental hazards. Source Adapted from da Silva et al. (2012)

- Behavior-The behavior network is much less tangible than the other three networks and includes the psychological and sociocultural factors at play in the system. It refers to the subjective qualities that can influence responses, actions, and decision making, including an individual's perception of a situation.

Information pertaining to each of the four long-term hazards identified in Fig. 2-arsenic water contamination; arsenic contamination of the food chain; indoor air quality pollution; and air pollution-was established through a systematic literature review using the following steps:

1. Identification of relevant bodies and organizations and identification of key terminology.

2. Search for grey literature using search engines (Google, Google Scholar, iDiscover) and organization webpages, plus peer-reviewed literature using academic databases (Scopus and Science Direct).

3. Use of literature references to identify new sources, assessment and comparison of the quality and relevance of the material.

4. Selection of final literature for incorporation in the analysis from 160 sources identified.

In addition to the systematic review of the selected literature quantitative data were sought from publicly available datasets published online by organizations such as the Bangladesh Bureau of Statistics, the United Nations International Children's Emergency Fund (UNICEF), the Emergency Events Database (EM-DAT), the Centre for
Research on the Epidemiology of Disasters (CRED), INFORM GRI (Index for Risk Management with technical lead by the European Commission Joint Research Centre), the United Nations Development Programme (UNDP), the United States Agency for International Development (USAID), and the World Bank.

\section{Systems View of Environmental Hazards}

The information gathered from the review was structured according to the system framework shown in Fig. 3 for four of the most significant environment hazards facing Bangladesh and the system interactions this reveals are reported below.

\subsection{Arsenic Contaminated Drinking Water}

The chemical element arsenic (As) is an omnipresent hazardous metal that mainly exists as an oxyanion compound in groundwater (Smedley and Kinniburgh 2002) and is considered to be the most significant chemical contaminant in drinking water globally (WHO 2018). In Bangladesh, 35-37 million people are prone to the chronic effects of this carcinogenic element (Nickson et al. 1998; Chaudhary et al. 2000; World Bank 2005; Murcott 2012; Johnston et al. 2014) resulting in an estimated 40,000 deaths per year (Pearshouse 2016). The issue is one of the most serious health problems in history because of the coupling between high groundwater concentrations of arsenic and a drinking water and irrigation system reliant on groundwater supply (World Bank 2005; Chakraborti et al. 2010; Johnston et al. 2014; Sharma et al. 2014). Millions of shallow tube wells have been installed and it is estimated that approximately $98 \%$ of the people in Bangladesh use groundwater for drinking (Shamsudduha et al. 2019). The affected aquifers are generally shallow at less than $100 \mathrm{~m}$ deep and the majority of tube wells are at a depth of 15-80 m, with arsenic concentration peaking at 20-70 m (Murcott 2012). 
More than $27 \%$ of the shallow groundwater aquifers in Bangladesh have been found to have As concentrations in excess of $50 \mu \mathrm{g} / \mathrm{l}$ (Khan et al. 2000; BGS and DPHE 2001) posing a serious threat to $90 \%$ of rural populations consuming the water from 4-5 million tube wells anchored in these shallow water aquifers (Ahmed et al. 2014). In 2009 an estimated 5.6 million people were exposed above $200 \mu \mathrm{g} / \mathrm{l}(200 \mathrm{ppb})$ and in extreme health danger (UNICEF 2011). This concentration is four times the Bangladesh standard and 20 times over the World Health Organization (WHO) guideline value (WHO 2018). It was estimated that in 2012 about 19 million people in Bangladesh were still exposed to arsenic concentrations above the national standard of $50 \mu \mathrm{g} / \mathrm{L}$, with fifty out of the 64 districts in the country having an arsenic concentration in the groundwater exceeding this level (Rahman et al. 2018). A total of 39 million people were exposed to arsenic concentrations above the WHO provisional guideline value of $10 \mu \mathrm{g} / \mathrm{L}$ (BBS/UNICEF 2015).

Chronic exposure to As in drinking water with a concentration greater than $50 \mu \mathrm{g} / \mathrm{l}$ can result in severe health problems (arsenicosis). These include symptoms of skin, cardiovascular, renal, hematological, and respiratory disorders (Smedley and Kinniburgh 2002), together with melanosis, skin cancer, peripheral neuropathy, gastrointestinal disorders, diabetes, cardiovascular disease, and cancers of internal organs-depending on the level of exposure (UNICEF et al. 2010; Murcott 2012). Arsenic poisoning will impair the intellectual function of children, reduce their cognitive abilities and IQ, and negatively impact their future well-being and educational potential (Wasserman et al. 2007; UNICEF et al. 2010; Rahman et al. 2018). Arsenicosis patients can face ostracism, social discrimination, and exclusion as society deems them as dangerous people. Hence patients will often conceal symptoms (Ahmad et al. 2007; Rahman et al. 2018). Women and children and the poorest segments of the population are the most vulnerable (Chowdhury et al. 2006). The solutions, problems, and key intervention points in the system are summarized in Fig. 4.

\subsubsection{Infrastructure}

Despite over 25 years of efforts to make progress towards the mitigation of the arsenic hazard, improvement is nowhere near satisfactory (Feroze Ahmed and Ahmed 2014; Pearshouse 2016; Rahman et al. 2018). Physical infrastructure can provide a range of solutions ranging from adopting alternative water sources or removal of arsenic through filters and chemical treatment. One of the key themes from the literature is that the most preferred alternative water source is the use of deep tube wells (DTWs) (approximately $>150 \mathrm{~m}$ deep) (Khan and Yang
2014) because the groundwater from deeper aquifers in arsenic-affected regions is for the most part free from contamination (Sharma et al. 2014). The primary drawback of DTWs is their high cost that is prohibitive for households without any subsidies or interventions, such that the technology is only applicable on a community basis (Sharma et al. 2014). This means individuals are likely to have increased walking distances to safe water, which has been shown to be a significant barrier and a reason why individuals persist in using contaminated wells (Shafiquzzaman et al. 2009; Johnston et al. 2014; Khan and Yang 2014). Recent evidence suggests that DTW users have poorer water quality at point of use, store water longer, and travel longer distances, increasing the risk of microbiological contamination (Goel et al. 2019).

There is uncertainty from institutional stakeholders regarding the recharge rates of the deep aquifers and the long-term sustainability of arsenic-free water (Khan and Yang 2014), with the concern that the use of DTWs could initiate the downward transport of arsenic contaminated water from shallow aquifers. However, as long as DTWs are used for domestic water and not irrigation, flow models have shown water from deep aquifers to be viable over the long term (Johnston et al. 2014; Sharma et al. 2014).

The use of surface water, rainwater harvesting, and dugwell water have the risk of potential biological contamination and require ongoing maintenance by the community, involving appropriate management and accountability (Johnston et al. 2014; Chakraborti et al. 2015). Piped water is a long-term aim and favored option, but the financial costs and practicalities of installation limit its current potential. However, there is already greater household willingness-to-pay for piped water supply than for other alternative arsenic-free water sources, primarily due to convenience (Khan et al. 2014). Due to the variability of arsenic contamination in shallow groundwater, it is possible in many locations to find uncontaminated wells within reasonable distances. Hence switching to a safe tube well is considered a viable solution (Sharma et al. 2014). This seems a straightforward option, but it relies on the identification, availability, and knowledge of safe wells, as well as the motivation of individuals to travel further and the absence of social barriers, that is, admittance to privately owned wells (Johnston et al. 2014). Furthermore, the arsenic concentration of wells can change over time, so together with its spatial variability it makes prediction virtually impossible (Sharma et al. 2014).

There is evidence that arsenic removal technologies are not a sustainable route to safe drinking water. Most widespread are household arsenic removal units such as the two-bucket treatment unit, three Kalshi filter unit, or the READ-F unit (Akter and Ali 2011; Luqman et al. 2013). Their reliance on maintenance and chemical replacement 
Fig. 4 System analysis of arsenic-contaminated drinking water in Bangladesh. UP: Upazila Parishad (subdistrict council)

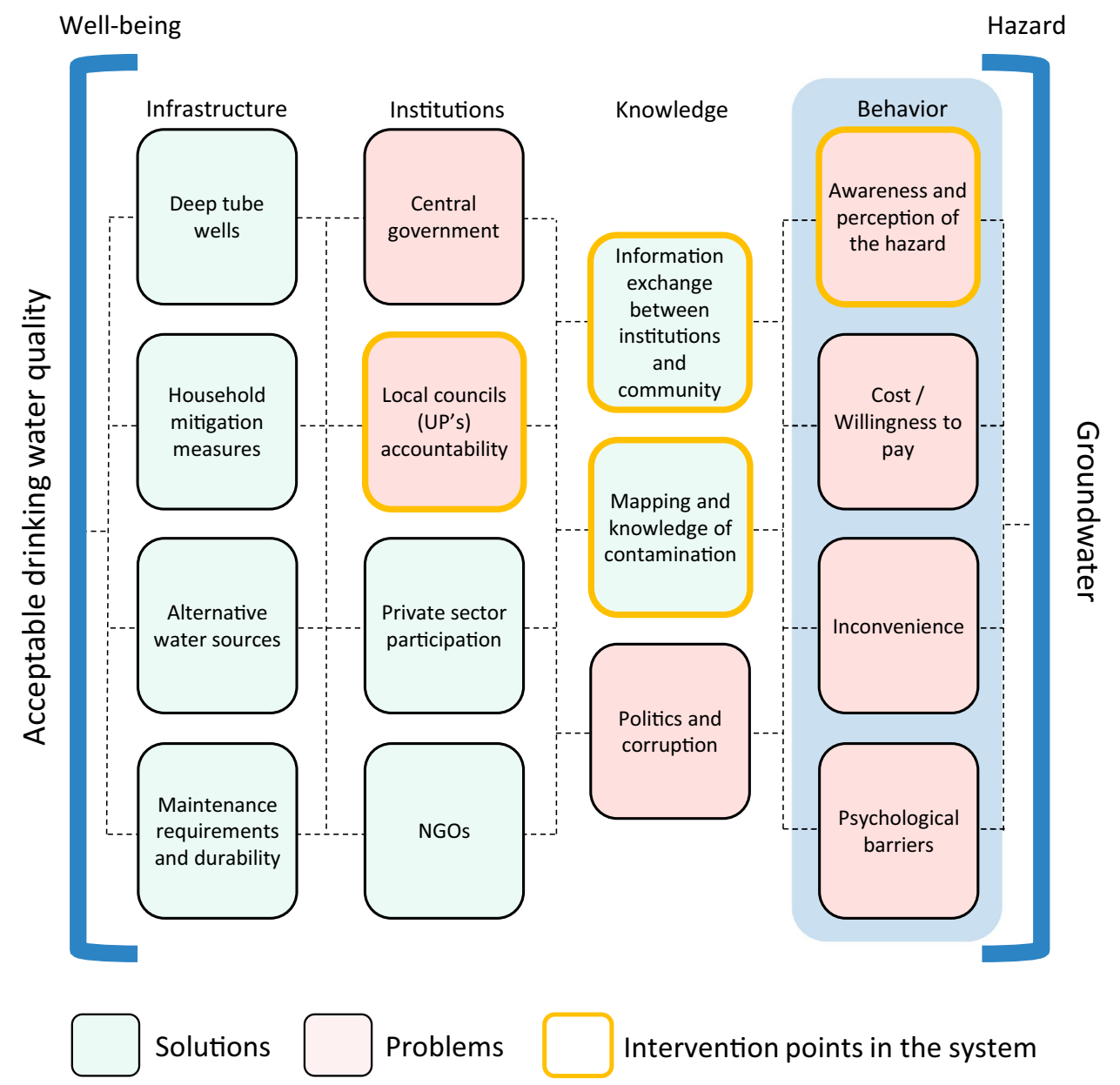

mean that although they are effective over the short term they cannot be considered a long-term solution. Other issues include inconvenience, disposal of arsenic wastes, and the low willingness-to-pay (Ravenscroft et al. 2009; Shafiquzzaman et al. 2009; Feroze Ahmed and Ahmed 2014; Sanchez et al. 2016; Bhattacharya et al. 2017). In a longitudinal study, Sanchez et al. (2016) measured urinary As in 600 Bangladesh households that had adopted READF filters and concluded that arsenic exposure could be temporarily reduced from a few weeks to a few months, but household treatment was not considered a sustainable arsenic mitigation option over the long term.

\subsubsection{Institutions}

The literature recognizes that lack of accountability and institutional weakness in the government of Bangladesh has hindered progress, particularly in the last 5-10 years (Johnston et al. 2014; Khan and Yang 2014; Bhattacharjee et al. 2019). The role of Upazila Parishad (UPs), subdistrict councils, has also been recognized, mainly because appropriate and sustainable mitigation solutions are context-specific and there is no blanket solution (Feroze Ahmed and Ahmed 2014; Johnston et al. 2014). Decentralization of power and strengthening UPs with experienced manpower, funding, and decision-making powers will help counteract the sluggish implementation of sustainable mitigation measures (Khan and Yang 2014).

A lack of multi-sectoral coordination, knowledge exchange, and collaboration between government departments, donor institutions, and NGOs to revise and implement policies quickly is a further hindering factor in arsenic mitigation (Khan and Yang 2014). Political nepotism and corruption concerns have been voiced by Human Rights Watch as a significant issue that is hampering effective mitigation efforts for those most in need (Pearshouse 2016).

\subsubsection{Knowledge}

Improved knowledge of arsenic prevalence and mapping the contamination levels of water sources enables better decision making for communities. Areas with low arsenic concentrations and arsenic-safe wells can be identified, 
thus promoting community confidence and increasing the popularity of well-switching (Feroze Ahmed and Ahmed 2014; Sanchez et al. 2016). Well-switching has to date had by far the largest impact in reducing arsenic exposure from drinking water (Sanchez et al. 2016).

Along with knowledge of safe wells, further information exchange between institutions and communities to build hazard awareness is vitally important. Efforts to communicate the life-threatening risks associated with drinking contaminated water will help to shift behaviors (Khan and Yang 2014; Sharma et al. 2014; Chakraborti et al. 2015). Due to the delay in the appearance of serious health symptoms, it is easy for individuals to misunderstand the severity of long-term health risks from drinking contaminated water. This knowledge factor is also intrinsically linked to the behavior network and the perception of the hazard (see Fig. 4).

Better understanding of groundwater flow to assess the viability of DTWs, together with the longer-term experience and collation of knowledge for various mitigation solutions, will help decision makers make more informed choices (Johnston et al. 2014; Sharma et al. 2014).

\subsubsection{Behavior}

Psychological, sociocultural, and behavioral factors have a major influence on the uptake and success of various mitigation solutions. The drivers of cost and convenience have been identified repeatedly (Johnston et al. 2014; Khan et al. 2014; Sharma et al. 2014). One study found that after just a year, $95 \%$ of participants had abandoned household filters primarily because of inconvenience, but also due to other influential factors including willingness-to-pay, ease of maintenance, and psychological barriers (Sanchez et al. 2016).

The willingness-to-walk (WTW) and willingness-to-pay (WTP) for safe water are closely tied to the perception of the hazard. Even with the knowledge that the water is contaminated, individuals will still use bad sources because the perceived health implications do not outweigh competing drivers. The delay of serious health impacts reduces the inconvenience threshold, so perception of the hazard and awareness of the benefits to clean water can overcome this obstacle (Khan et al. 2014). Inconvenience of additional walking distances and opportunity cost of time commitment are limitations to community-based measures and use of DTWs (Shafiquzzaman et al. 2009; Johnston et al. 2014; Khan and Yang 2014). Similarly, maintenance requirements of arsenic removal technologies and poor flow rates lead to their abandonment (Sanchez et al. 2016). Cost is a key limitation and the WTP is generally very low, hence the required capital investments make many solutions cost-prohibitive for household-scale solutions (Johnston et al. 2014; Khan et al. 2014; Sanchez et al. 2016).
In terms of psychology it has been found that the descriptive norm and self-efficacy are important factorsthe perception that water collection from safe wells is socially normal and that people are confident in being able to do so over the long term (Inauen and Mosler 2014; Johnston et al. 2014). Additionally, as women are predominantly responsible for collecting water, communitybased solutions can carry social, religious, and psychological barriers (Khan and Yang 2014).

\subsection{Arsenic Food Chain Contamination}

A growing concern is the new or increased exposure to arsenic through the food chain (Fig. 5), compounding any existing poisoning from contaminated drinking water (Rahman et al. 2018). Kawser Ahmed et al. (2016) reported that the estimated daily dietary intakes (EDI) of inorganic arsenic for exposed rural and urban residents were 3.5 and $3.2 \mu \mathrm{g} / \mathrm{kg}-\mathrm{BW} / \mathrm{day}$, respectively, and clearly exceeded the previously provisional tolerable daily intake value of $2.1 \mu \mathrm{g} / \mathrm{kg}-\mathrm{BW} /$ day, recommended by WHO (2011). There are numerous exposure pathways, whether from eating crops grown in or irrigated by contaminated water; consuming livestock that have been fed with contaminated food/water, or through the use of arsenic-rich water in preparing meals. Groundwater is extensively used for irrigation in the dry season and rice is the most important food group with respect to exposure (Sharma et al. 2014). Arsenic contamination can lead to reduced crop yields and exacerbate food insecurity (Dittmar et al. 2007). Polizotto et al. (2013) indicated that extensive use of arsenic-contaminated groundwater for irrigation during the dry season threatens the expansion of rice production in Bangladesh.

Research and understanding of arsenic exposure through these pathways is less developed than for drinking water. Decreasing exposure at the point of consumption, limiting any arsenic accumulation in the crops or soil, and tackling falling crop yields are the focus of efforts (Senanayake and Mukherji 2014). Mitigation strategies for reducing arsenic contamination of cooking water and reducing exposure through food are often overlooked (Sharma et al. 2014). Such mitigation options vary from place to place and depend on the end users.

\subsubsection{Infrastructure}

One of the primary areas for mitigation surrounds the use of deficit irrigation schemes such as aerobic cultivation and intermittent ponding, which have been shown to reduce the concentrations of arsenic in the rice without significantly reducing the yield (Senanayake and Mukherji 2014; Basu et al. 2015; Mukherjee et al. 2017). These schemes promote water efficiency as irrigation is limited and puts the 
Fig. 5 System analysis of food chain arsenic contamination in Bangladesh. As: Arsenic

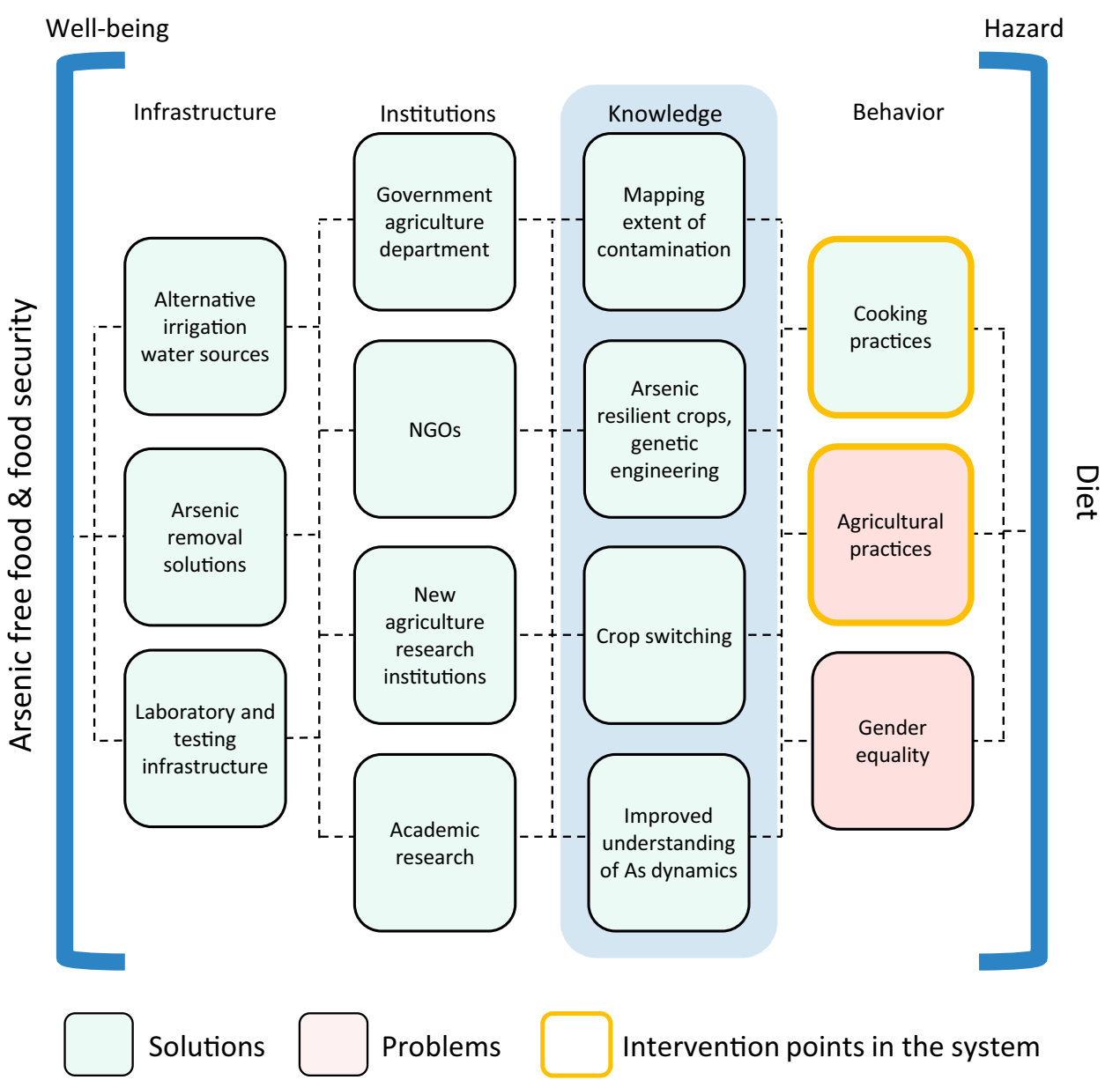

crops under a certain degree of water stress. However, given that most surface waters have been exploited for irrigation and the high probability that farmers will continue to use groundwater for irrigation, adopting these mitigation strategies is a crucial step in limiting the exposure (Senanayake and Mukherji 2014). Except where As concentrations in shallow groundwater are observed to decline rapidly, Brammer and Ravenscroft (2009) suggested that the only permanent alternatives to non-irrigated cropping patterns will be to exploit deeper aquifers or surface-water sources. However, they recognize the exploitation of deeper aquifers for irrigation is extremely uncertain as their resource potential is unquantified and the sustainability of these sources, even for potable water, is questioned.

In combination with the institutional and knowledge networks, additional research resources such as laboratory infrastructure and science and technology facilities may be key in developing the understanding required to arrive at appropriate recommendations (Brammer 2009).

\subsubsection{Institutions}

The government of Bangladesh has a central role to play in future developments. Accountability is key, and policy interventions or regulations can instigate real change. At present there is no management plan or regulation set by the agriculture department of the Bangladesh government (Sharma et al. 2014). A proactive approach is required for the management of all arsenic-free water sources (particularly for irrigation), and regulation of permissible arsenic concentrations in the water and soil for agricultural production is needed (Sharma et al. 2014; Ahmed et al. 2016). Collaboration is required at all levels between the government, NGOs, academic institutions, and the private sector for mitigation, awareness programs, and knowledge advancement (Ahmed et al. 2016).

\subsubsection{Knowledge}

The need to advance current understanding of the spatial prevalence and the mechanisms of arsenic uptake in food stuffs is a recurring theme across the literature (Brammer 2009; Zhao et al. 2010; Senanayake and Mukherji 2014; 
Sharma et al. 2014). Investigation of the complete food chain in arsenic-affected zones and the development of a toxicity database of crops is seen as an essential tool, as this can be used to set standards for soil concentrations (Senanayake and Mukherji 2014; Bhattacharya et al. 2017). Mapping the magnitude of soil and crop contamination, together with the population affected by food-chain contamination, will enable the prioritization of attention and the best use of limited resources (Sharma et al. 2014).

Genetic engineering of crops to create more tolerant plants that have a reduced uptake of arsenic from contaminated water and soil is a proposed route to food safety (Carbonell-Barrachina et al. 2009; Zhao et al. 2010). Although these engineered crops will reduce the amount of arsenic uptake, they will not influence the soil or water concentrations, meaning that soil arsenic levels will continue to rise (Senanayake and Mukherji 2014). Therefore, genetically engineered crops are not a sustainable solution in isolation, and arsenic-safe irrigation water must be sought alongside this mitigation strategy.

Rice accumulates higher concentration of As in grains than other cereals (Bakhat et al. 2017) so switching to dryland crops such as wheat and maize instead of planting rice has the potential to decrease the build-up of arsenic in the soil and the produce (Brammer 2009; Sharma et al. 2014). Dryland crops require less irrigation, which not only means that less arsenic-contaminated water is used, limiting plant uptake and soil concentrations, but the cultivation costs are also reduced. Understanding how the interventions can be combined for maximum effect and the feasibility of scaling up should be a focus of future efforts (Senanayake and Mukherji 2014).

\subsubsection{Behavior}

Simple changes in the processing of food can help to reduce the arsenic intake and a key enabler of this mitigation strategy is the availability and use of safe drinking water (Carbonell-Barrachina et al. 2009). Using high volumes of arsenic-free water to cook contaminated rice and vegetables reduces the concentration of arsenic in the diet, as opposed to using arsenic-affected water that compounds the exposure (Carbonell-Barrachina et al. 2009; Sharma et al. 2014; Basu et al. 2015). This is heavily dependent on the perception of the hazard and the motivation of households to use safe drinking-water sources wherever possible, despite potential inconveniences.

One study showed that arsenic mainly accumulates in the roots and the skin of crops. In areas of polluted water, mechanical de-husking and peeling should be employed to minimize the use of water, instead of using more traditional "wet" systems of preparation (Carbonell-Barrachina et al. 2009).
Whether it is in agricultural methods or cooking practices, the change of behaviors needs to be achieved by increasing the awareness of the population of the long-term risks of arsenic exposure, incentivizing household mitigation efforts. The level of understanding of this pathway is much less developed than that of drinking water, and there are significant knowledge gaps-at this stage, the knowledge network is key to addressing the hazard (see Fig. 5).

\subsection{Household Air Quality}

In Bangladesh lower-income households in peri-urban and rural areas rely primarily on biomass fuels, and these produce high emissions that have significant health impacts (WHO 2014). These biomass sources range from cow dung to wood, charcoal, and crop residues that can be collected daily and are burned on traditional cooking stoves inside the home (Begum et al. 2009; Miah et al. 2009; Quansah et al. 2017). Such fuels are used because of the unavailability and cost of alternatives (Miah et al. 2009; Alim et al. 2013). Millions of people are exposed to harmful air pollution predominantly from household air pollution (HAP) (Fig. 6) because $82 \%$ of households still use such solid fuels for cooking (NIPORT et al. 2016).

In adults exposure leads to the onset of non-communicable diseases and conditions such as chronic obstructive pulmonary disease, ischemic heart disease, strokes, and lung cancer (WHO 2016). For children HAP heightens the risk from asthma, respiratory infections, congenital abnormalities, and adverse neonatal conditions, and negatively affects cognitive development (WHO 2016, 2017b). The leading cause of death in young children in Bangladesh is respiratory tract infections from exposure to particulate matter (Gurley et al. 2013). The burning of solid biomass fuel can also cause death and serious injury from burns and scalds (WHO 2014). The key pollutant is $\mathrm{PM}_{2.5}$ and a reduction in this fine particulate matter to low levels will achieve the greatest health benefit (WHO 2014).

Women and children are the most susceptible to this hazard. Women spend the most time indoors in close proximity to the stove (Banik 2017). Women and children are also vulnerable to injury and violence when out collecting fuel, and the time-consuming activity of gathering fuel detracts from other productive activities and keeps children away from school (WHO 2014).

\subsubsection{Infrastructure}

Progress to address this hazard has been slow, underfunded, and hampered by ineffective and unsustainable interventions (WHO 2014). Many initiatives focus on engineering a solution with the design and manufacture of improved cookstoves (ICS) to replace the traditional 
Fig. 6 System analysis of household air pollution in Bangladesh

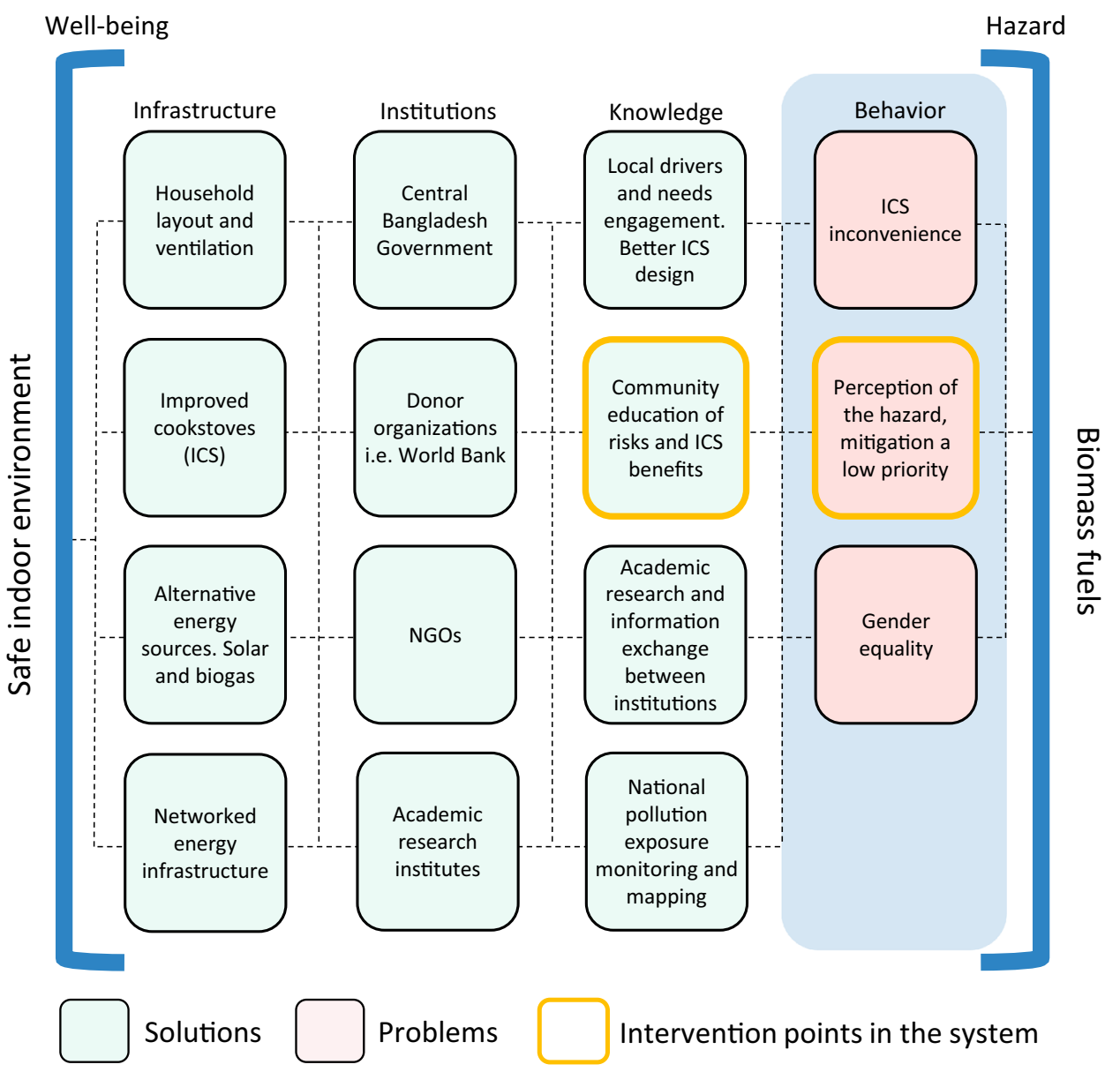

cookstoves (TCS). These ICS seek to maximize fuel and thermal efficiency, improve safety, and limit exposure to emissions, but they must also be low cost to be affordable for the poor (Miah et al. 2009; Urmee and Gyamfi 2014). Demand and uptake have been low (Mobarak et al. 2012; Urmee and Gyamfi 2014; Quansah et al. 2017). Although there have been many cookstove intervention programs, there is still considerable uncertainty as to their effectiveness (Urmee and Gyamfi 2014; Quansah et al. 2017).

The adoption of alternative, cleaner fuels such as liquefied petroleum gas (LPG), biogas, and solar energy is one of the most effective ways to limit indoor air pollution from particulate matter (Begum et al. 2009; Junaid et al. 2018). However, these alternatives would rely on the introduction of low-cost efficient cookers that require a household investment (Miah et al. 2009). Importantly, characteristics such as the time a cooker takes to heat up, social status, and aesthetics are perceived by users to hold more value than fuel economy-the characteristic the design focuses on (Urmee and Gyamfi 2014).

Improving the ventilation and layout of kitchens has been cited as more cost-effective as it is already within the means of poor families and prevents the need to switch to more costly fuels or technology (Begum et al. 2009; Junaid et al. 2018). Open kitchen layouts with more external doors and windows decrease particulate matter concentrations and mitigate the hazard effectively. Begum et al. (2009) found that fuel choice is secondary to the multiple factors that affect ventilation in households-evidence shows that some kitchen layouts are capable of providing relatively clean conditions in terms of particulate matter concentrations even when dirty biomass fuels are used.

\subsubsection{Institutions}

Early initiatives to combat the problem involved collaboration between government organizations, donor agencies, and NGOs to disseminate cookstoves. Multi-sectoral collaboration can have real benefits, especially to lower the cost and liquidity barriers many households face (Mobarak et al. 2012). However, a top-down approach must take into account the end user needs because users value characteristics outside of the technical solution, which can be critical in ICS adoption rates (Urmee and Gyamfi 2014).

With subsidies and government intervention through policy, the use of clean fuels could be proliferated and the 
adoption of ICS accelerated (Miah et al. 2009; Banik 2017; Junaid et al. 2018). Urmee and Gyamfi (2014) reasoned that subsidies should also be provided for training local ICS designers and manufacturers who can pass on knowledge to the users, rather than to just subsidize the cost for poor families, making the initiative more sustainable, as many ICS programs have collapsed with the end of donor funding. Communicating the hazard is important and can be achieved using social media and through health professionals to strengthen the public awareness and understanding of the health risks (Chowdhury et al. 2011; Alim et al. 2013; Junaid et al. 2018).

\subsubsection{Knowledge}

Cooking practices change throughout the year and the seasonal differences in HAP particulate matter needs to be better understood (Begum et al. 2009; Gurley et al. 2013). Low levels of education have been associated with poor women's low awareness of the health impacts of HAP (Banik 2017).

In themselves, risk awareness campaigns are not likely to be enough to change cooking practices (Mobarak et al. 2012). There is a need for closer engagement with communities and the assessment of local priorities and desirable characteristics to make progress in the design of ICS and heighten the perceived value to counteract household budgetary concerns (Mobarak et al. 2012; Urmee and Gyamfi 2014).

\subsubsection{Behavior}

The primary barrier to the adoption of ICS is financial, but this is coupled with the fact that HAP is not perceived as a significant health hazard, and so directing attention to other basic development needs is required as well (Mobarak et al. 2012; Urmee and Gyamfi 2014). Many households do not perceive indoor air quality as a high priority. Thus, factors in the behavior network are key, but they are addressed through action in the other three networkseducation, involvement of institutions, and infrastructure changes, showing the interconnected nature of the system (see Fig. 6). A key intervention point is community education about risks, and raising awareness of improved cooking stove benefits is vital.

\subsection{Ambient Air Quality}

In urban areas of Bangladesh, ambient air pollution is the leading cause of morbidity and mortality (see Fig. 7). The major contributors to extensive pollution are vehicle emissions, road dust, brick kilns, and biomass combustion (World Bank 2008; Begum et al. 2014)—15,000 deaths due to air pollution are recorded each year (Mahmood 2011; Pearshouse 2016). The mean concentration for $\mathrm{PM}_{2.5}$ has been measured at $135 \mu \mathrm{g} / \mathrm{m}^{3}$ in Dhaka (Khan et al. 2019), compared to $11-20 \mu \mathrm{g} / \mathrm{m}^{3}$ in several US cities such as Los Angeles (Krzyzanowski et al. 2014).

\subsubsection{Infrastructure}

Strategies to reduce vehicle emissions have included the conversion of petrol and diesel vehicles to compressed natural gas (CNG), increasing traffic speed, and improving maintenance requirements for commercial vehicles (Rahman et al. 2008; Begum et al. 2011). Despite these positive initiatives, improvements to public transport road infrastructure are required (World Bank 2008; GoB DoE 2012). Soil dust particulate matter from unpaved roads and intensifying construction activities is also increasing (Rahman et al. 2008; GoB DoE 2012; Guttikunda et al. 2013). Transport planning and mass transit systems need to be addressed in order to improve mobility and decrease the intensifying emissions, but are struggling to keep up with demand (Mahmood 2011).

Use of cleaner energy, such as natural gas, has the potential to make a considerable difference to industrial emissions. However, there is no nationwide gas supply network and where networks exist, supply is unreliable (GoB DoE 2012; Begum and Hopke 2018) and high costs provide little incentive for business owners to invest in technological improvements (Luby et al. 2015).

\subsubsection{Institutions}

National government policies have been focussed on reducing vehicular emissions and eliminating the worst offenders (Begum et al. 2011). In 2003, commercial 2 -stroke engines were banned along with buses and trucks over 20 years old, and since then there has been a shift to the use of CNG over petrol/diesel, including the conversion of buses (Begum et al. 2011; Begum and Hopke 2018). There have been various collaborative initiatives to reduce air pollution. The Clean Air and Sustainable Environment (CASE) program is one example in which the World Bank is funding the government of Bangladesh to improve air quality in Dhaka (World Bank 2017). The project looks to introduce cleaner technology, improve efficiency, and sustain air quality management initiatives (World Bank 2008, 2017; Mahmood 2011).

Lack of law enforcement and weak institutional governance are inhibitors to action (World Bank 2008; Guttikunda et al. 2013; Luby et al. 2015). Currently, monitoring and enforcement is negligent—brick kilns, for example, use banned coal with high sulphur content 
Fig. 7 System analysis of air quality in Bangladesh

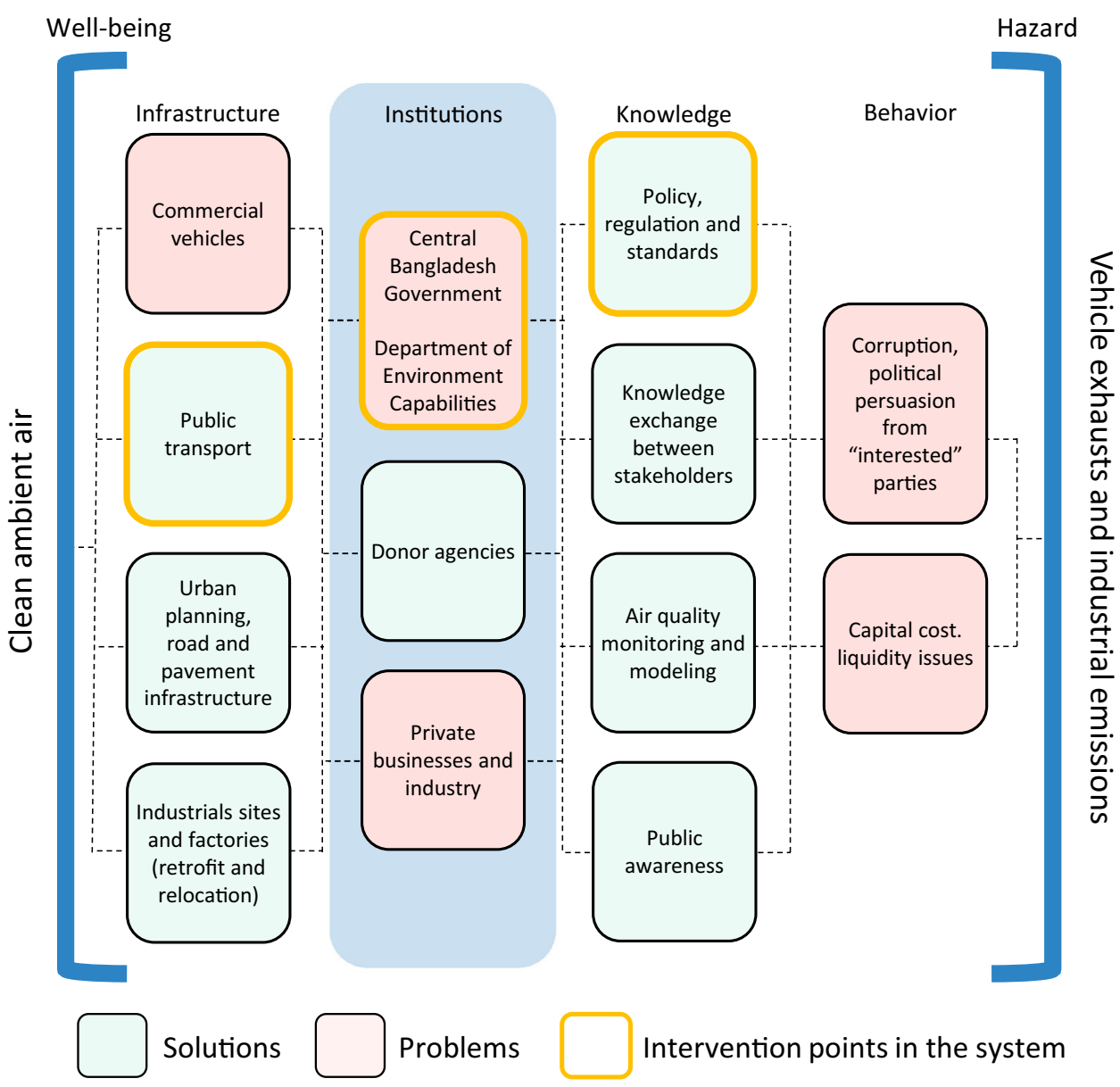

because the ban is overturned each year, an important weakness that needs to be addressed (GoB DoE 2012).

\subsubsection{Knowledge}

Efforts to increase air quality monitoring to better the understanding of air pollution concentrations and health impacts are necessary (Krishna et al. 2017). This will further enable the prediction, assessment, and mitigation of air pollution on local, regional, and national scales and drive action from policymakers (Mahmood 2011; Guttikunda et al. 2013; Krishna et al. 2017). Furthermore, the power of mass media reporting to raise public awareness can be a substantial driver to prompt government action (World Bank 2008; Begum and Hopke 2018).

Knowledge sharing between institutions and stakeholders at all levels is critical to a coordinated approach to understanding the hazard and the mitigation solutions available, including conveying the importance of inspection and maintenance of commercial vehicles, communicating fuel and lubricant regulations, and eliminating the knowledge gap in how to construct improved chimneys for brick kilns (Begum et al. 2011, 2013; Luby et al. 2015; Krishna et al. 2017; Begum and Hopke 2018).

\subsubsection{Behavior}

Incentives are needed for stakeholders to act differently. Currently, many technological improvements are capitalintensive and cost-prohibitive, and regulations are not typically enforced (GoB DoE 2012; Luby et al. 2015). Relevant institutions such as the Department of Environment need to be strengthened, to enable autonomy and increased capacity to act and enforce regulations, eliminate any corruption and minimize political leverage from industry stakeholders (see Fig. 7). The key emergent themes arising from this review are summarized in Table 1.

\section{Discussion}

All of the long-term stresses reviewed above are continually present, but they can be differentiated by the duration of exposure (Fig. 8). Contact with urban air pollution is unavoidable and affects everyone in a location. However, 
Table 1 Key emergent trends in arsenic and air pollution mitigation strategies in Bangladesh

\begin{tabular}{|c|c|c|c|c|}
\hline & $\begin{array}{l}\text { Arsenic contaminated } \\
\text { drinking water }\end{array}$ & $\begin{array}{l}\text { Arsenic food chain } \\
\text { contamination }\end{array}$ & Household air quality & Ambient air Quality \\
\hline Infrastructure & $\begin{array}{l}\text { Deep tube wells are the best } \\
\text { alternative water source } \\
\text { with piped supply as the } \\
\text { long-term goal to reduce } \\
\text { inconvenience barriers }\end{array}$ & $\begin{array}{l}\text { Deficit irrigation and the use } \\
\text { of surface water are } \\
\text { preferable to deep tube } \\
\text { wells. Lack of technical } \\
\text { solutions to remove arsenic }\end{array}$ & $\begin{array}{l}\text { Increased ventilation in the } \\
\text { home and use of doors and } \\
\text { windows can make an } \\
\text { immediate difference } \\
\text { without any capital cost }\end{array}$ & $\begin{array}{l}\text { Improved infrastructure can } \\
\text { induce behavioral change } \\
\text { and a shift from private } \\
\text { vehicles to public transport, } \\
\text { walking, and cycling }\end{array}$ \\
\hline Institutions & $\begin{array}{l}\text { Government accountability } \\
\text { and the strengthening of } \\
\text { Upazila Parishad powers }\end{array}$ & $\begin{array}{l}\text { Government action plan and } \\
\text { regulation. New } \\
\text { agricultural institutions } \\
\text { and research facilities } \\
\text { could provide } \\
\text { breakthrough insights } \\
\text { required to promote action }\end{array}$ & $\begin{array}{l}\text { Government subsidies and } \\
\text { donor organizations have a } \\
\text { great ability to break down } \\
\text { the cost barrier to the } \\
\text { adoption of improved cook } \\
\text { stoves }\end{array}$ & $\begin{array}{l}\text { Overwhelmingly focus falls } \\
\text { on the government and } \\
\text { Depart of Environment to } \\
\text { implement and enforce } \\
\text { regulation, with } \\
\text { enforcement the priority }\end{array}$ \\
\hline Knowledge & $\begin{array}{l}\text { Improving mapping of the } \\
\text { hazard and increasing risk } \\
\text { awareness }\end{array}$ & $\begin{array}{l}\text { Mapping the extent of } \\
\text { contamination and the } \\
\text { worst affected areas. } \\
\text { Assessing the feasibility } \\
\text { and potential of mitigation } \\
\text { solutions }\end{array}$ & $\begin{array}{l}\text { Community education in the } \\
\text { risk. Cook stoves are not } \\
\text { adopted due to a low } \\
\text { perceived value compared } \\
\text { to their cost and design } \\
\text { issues }\end{array}$ & $\begin{array}{l}\text { Awareness of air pollution is } \\
\text { high but improved } \\
\text { monitoring, modeling, and } \\
\text { reporting help to drive } \\
\text { change by policymakers }\end{array}$ \\
\hline Behavior & $\begin{array}{l}\text { The convenience of shallow } \\
\text { tube wells is a major } \\
\text { barrier to the adoption of } \\
\text { alternative water sources } \\
\text { and the use of arsenic } \\
\text { removal technologies }\end{array}$ & $\begin{array}{l}\text { Changing cooking practices } \\
\text { can have significant impact } \\
\text { on exposure but relies on } \\
\text { education and awareness }\end{array}$ & $\begin{array}{l}\text { Women and children are } \\
\text { impacted } \\
\text { disproportionately, } \\
\text { addressing inequality is } \\
\text { crucial to mitigate impacts, } \\
\text { especially for children }\end{array}$ & $\begin{array}{l}\text { Improved infrastructure can } \\
\text { change people's behavior } \\
\text { from private vehicles to } \\
\text { public transport, walking, } \\
\text { and cycling }\end{array}$ \\
\hline $\begin{array}{l}\text { Key } \\
\text { intervention } \\
\text { point }\end{array}$ & $\begin{array}{l}\text { Institutions: decentralization } \\
\text { of decision making and } \\
\text { strengthening of local } \\
\text { councils } \\
\text { Knowledge: improving } \\
\text { information exchange } \\
\text { between institutions and } \\
\text { communities, improving } \\
\text { mapping of contaminated } \\
\text { sources } \\
\text { Behavior: changing } \\
\text { perception of the hazard and } \\
\text { benefits of clean water }\end{array}$ & $\begin{array}{l}\text { Behavior: changing } \\
\text { household processing of } \\
\text { food; switching to } \\
\text { alternative crops }\end{array}$ & $\begin{array}{l}\text { Knowledge: changing risk } \\
\text { perception }\end{array}$ & $\begin{array}{l}\text { Infrastructure: improvements } \\
\text { in walking, cycling, and } \\
\text { public transport } \\
\text { Institutions: empowerment of } \\
\text { Department of Environment } \\
\text { with greater enforcement of } \\
\text { regulatory power } \\
\text { Knowledge: better monitoring } \\
\text { to drive policy regulation } \\
\text { and standards }\end{array}$ \\
\hline
\end{tabular}

with arsenic contamination and indoor air quality, individuals have greater opportunity (and in some cases the choice) to prevent their personal exposure to the hazard through behavioral changes, given the knowledge of the hazard and access to possible mitigation actions.

For all the hazards there exist short-term mitigation solutions and long-term strategies to eliminate the hazard entirely. In all hazards, uncertainty is a consistent factor. There is a recognized need for better understanding of the extent of the exposures, the health implications, and the economic impacts to stimulate action. But empirical studies into the effectiveness of mitigation solutions to inform decision making are required as well. Addressing the knowledge gaps - such as those related to the sustainability of deep tube wells, or the valued features that drive the uptake of improved cookstoves-will help build a unified response, rather than fragmented and sporadic efforts (World Bank and IHME 2016).

The inclusion of the behavior network in the preceding analysis captures some of the less tangible, but influential factors in the mitigation of the hazards. Of note is the perception of the hazard. This influences the decisions made by individuals at risk through their willingness-topay or the level of inconvenience they are prepared to accept to reduce exposure. In all hazards, improved knowledge and understanding is important for effective hazard mitigation.

The enormity of the hazards, and the extended time frame over which they have developed, leads to a lack of responsibility and accountability of institutions. Numerous 
Fig. 8 Differentiating environmental hazards in Bangladesh

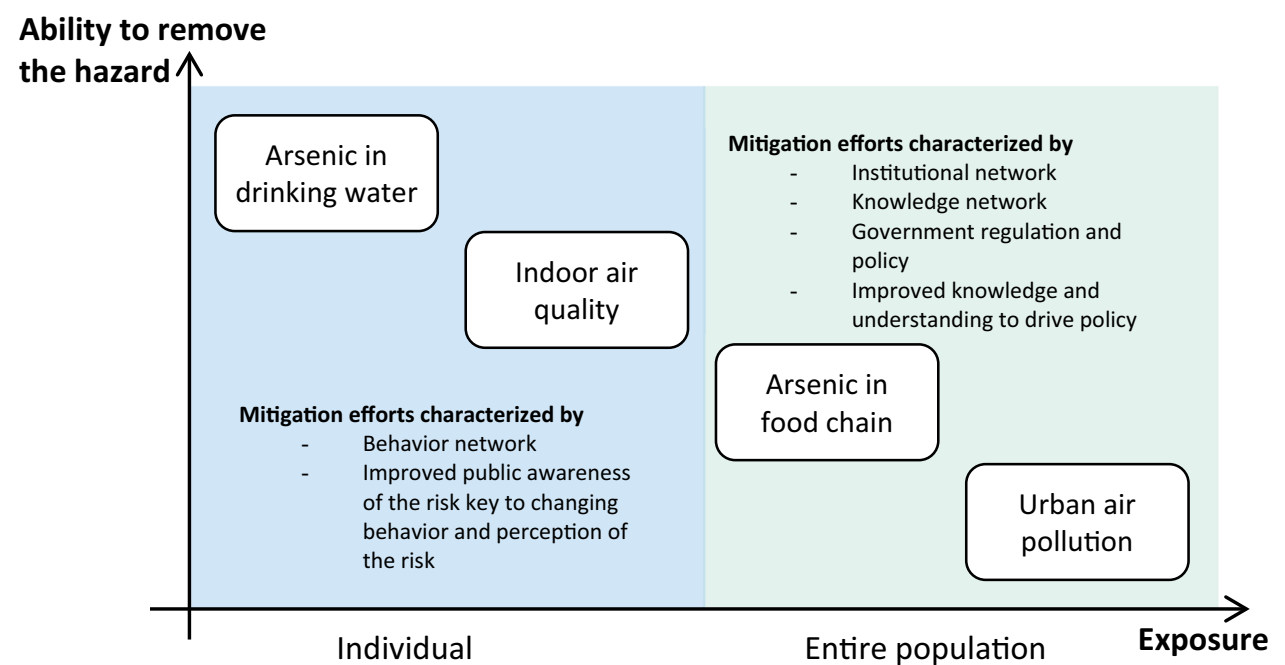

stakeholders at various levels make the response multidimensional, which in part contributes to a lack of sustained action as they operate with different capabilities and goals.

Even if the hazards were immediately mitigated, there would still be health repercussions for years to come due to the delay in the onset of non-communicable diseases (Krajick and Funkhouser 2015). The delayed onset of serious health implications is a significant factor in the system as it affects both the behavior and decisions made by individuals exposed to the hazards, but also the response and action delivered by institutions. The delay in health impacts creates indecisiveness as the urgency is masked and leads to a lack of accountability by policymakers, especially when the prevalence and effects are still being quantified. From the analysis, a high-level characteristic profile that describes the response to stresses is shown in Fig. 9.

The ongoing stresses map onto different points in Fig. 9, with different interventions suitable for each hazard, based on their position in the time line. In developing effective responses a focus on education must be a priority because changes in household knowledge, attitudes, and practices are essential. Often change is resisted due to a lack of understanding of the danger, with convenience prevailing over hazard mitigation (UNICEF 2013). One effective route to improving education could be through the use of schools, training teachers to disseminate the risk knowledge to the students. This not only has a wide reach, but means knowledge stays within the community and is provided by trusted individuals (Khan et al. 2015).

Improving the role of government is a key recommendation. Updating and implementing national management plans to a coherent strategy with quantifiable targets will help provide direction (Pearshouse 2016; Krishna et al. 2017). However, speeding up implementation requires strengthening the capacity of national agencies and the subdistrict councils by giving them greater decision-making powers, increased funds, and trained manpower.
Fig. 9 Profile of responses to stresses in Bangladesh

\section{Response profile for stresses}

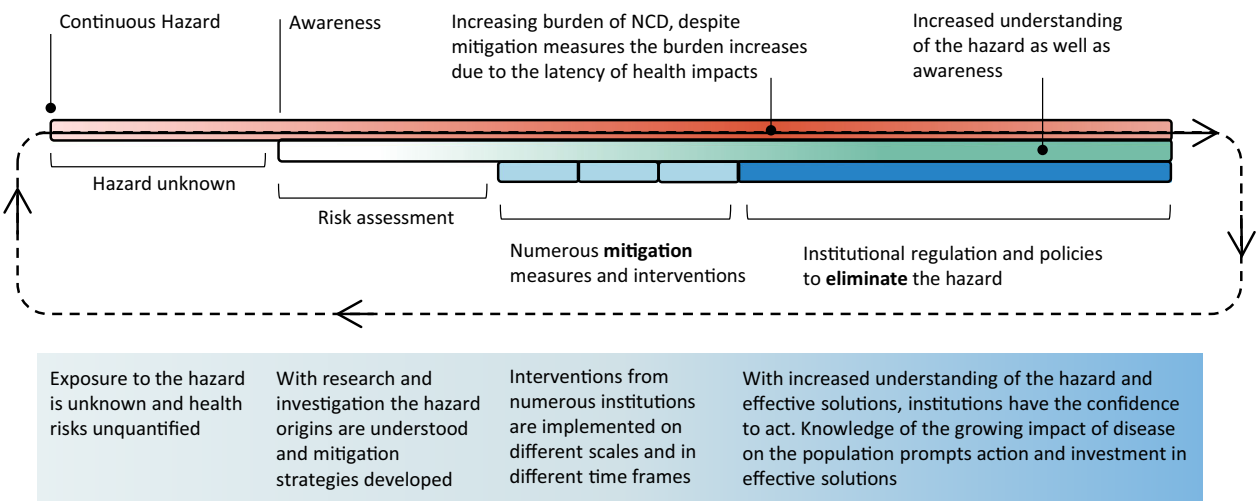


Actions are needed to enforce regulation and eliminate political interference (Johnston et al. 2014; Luby et al. 2015; Ellis and Roberts 2016). The focus on non-communicable diseases in the healthcare system is currently less than optimal, and it is not helped by a critical shortage of skilled healthcare professionals (Islam and Biswas 2014; Islam 2017). There is an urgent need to strengthen the system so that it can respond more effectively to the growing burden and limit the declining health across the Bangladeshi population (Bleich et al. 2011; Islam and Biswas 2014). Health is a fundamental prerequisite for disaster resilience because without it the ability to achieve good social interaction, sufficient material conditions, and personal security are diminished (Ray-Bennett et al. 2010; Hossain et al. 2016).

\section{Conclusion}

A framework consisting of four networks was used to link the well-being of the Bangladeshi population to the environmental hazards that generate chronic stress in the population. This framework has facilitated cross-comparison between the four prevalent environmental stresses and an insight into the underlying system responses, highlighting barriers to effective mitigation that are in turn hindering the response capacity of the population. Elimination of the continuous hazards will only come about through the culmination of multiple interventions over time, in an iterative manner that relies on the continual advance of hazard understanding. The analysis revealed the significance of behavioral factors in the adoption of mitigation solutions. Equally, improved knowledge and understanding is central to the mitigation of all hazards. Underlying system characteristics, such as the delay in health implications and the sheer magnitude of the hazards, are significant barriers to effective mitigation.

Acknowledgements This research was conducted as part of the Cambridge Alliance to Protect Bangladesh from Long-term Environmental hazards (CAPABLE), an interdisciplinary program funded by the UK Research Councils' Global Challenges Research Fund, under Grant MR/P02811X/1. The views expressed are those of the authors and do not necessarily represent those of the wider consortium.

Open Access This article is distributed under the terms of the Creative Commons Attribution 4.0 International License (http://crea tivecommons.org/licenses/by/4.0/), which permits unrestricted use, distribution, and reproduction in any medium, provided you give appropriate credit to the original author(s) and the source, provide a link to the Creative Commons license, and indicate if changes were made.

\section{References}

Ahmad, S.A., M.H.S. Sayed, M.H. Khan, M.N. Karim, M.A. Haque, M.S.A. Bhuiyan, M.S. Rahman, and M.H. Faruquee. 2007. Sociocultural aspects of arsenicosis in Bangladesh: Community perspective. Journal of Environmental Science and Health Part A 42(12): 1945-1958.

Ahmed, S., S.E. Moore, M. Kippler, R. Gardner, M.D.H. Hawlader, Y. Wagatsuma, R. Raqib, and M.Vahter. 2014. Arsenic exposure and cell-mediated immunity in pre-school children in rural Bangladesh. Toxicological Sciences 141(1): 166-175.

Ahmed, M.K., N. Shaheen, M.S. Islam, M. Habibullah-Al-Mamun, S. Islam, M.M. Islam, G.K. Kundu, and L. Bhattacharjee. 2016. A comprehensive assessment of arsenic in commonly consumed foodstuffs to evaluate the potential health risk in Bangladesh. Science of the Total Environment 544: 125-133.

Akter, A., and M.H. Ali. 2011. Arsenic contamination in groundwater and its proposed remedial measures. International Journal of Environmental Science and Technology 8(2): 433-443.

Akter, S., and B. Mallick. 2013. The poverty-vulnerability-resilience nexus: Evidence from Bangladesh. Ecological Economics 96: 114-124.

Alam, G.M.M., K. Alam, S. Mushtaq, and W.L. Filho. 2018. How do climate change and associated hazards impact on the resilience of riparian rural communities in Bangladesh? Policy implications for livelihood development. Environmental Science \& Policy 84: 7-18.

Alim, M.A., A.S.M. Nurunnabi, S. Ahmad, M.A. Khan, and S.A. Ahmad. 2013. Knowledge of health hazards and perception of prevention amongst females exposed to biomass fuel and gas/electricity fuel in a district of Bangladesh. Anwar Khan Modern Medical College Journal 4(1): 20-24.

Ayeb-Karlsson, S., K. van der Geest, I. Ahmed, S. Huq, and K.Warner. 2016. A people-centred perspective on climate change, environmental stress, and livelihood resilience in Bangladesh. Sustainability Science 11(4): 679-694.

BBS/UNICEF (Bangladesh Bureau of Statistics/United Nations International Children's Emergency Fund). 2015. Multiple indicator cluster survey 2012-13: Final Report. Dhaka: Bangladesh Bureau of Statistics/UNICEF.

Banik, B.K. 2017. An exploration of poor female understanding about health hazards of indoor air pollution in Bangladesh. Journal of Environments 4(1): 1-8.

Bakhat, H.F., Z. Zia, S. Fahad, S. Abbas, H.M. Hammad, A.N. Shahzad, F. Abbas, H. Alharby, and M. Shahid. 2017. Arsenic uptake, accumulation and toxicity in rice plants: Possible remedies for its detoxification: A review. Environmental Science and Pollution Research 24(10): 9142-9158.

Basu, B., M. Kundu, M. Hedayatullah, C.K. Kundu, P. Bandyopadhyay, K. Bhattacharya, and S. Sarkar. 2015. Mitigation of arsenic in rice through deficit irrigation in field and use of filtered water in kitchen. International Journal of Environmental Science and Technology 12(6): 2065-2070.

Begum, B.A., and P.K. Hopke. 2018. Ambient air quality in Dhaka Bangladesh over two decades: Impacts of policy on air quality. Aerosol and Air Quality Research 18(7): 1910-1920.

Begum, B.A., S.K. Biswas, and P.K. Hopke. 2011. Key issues in controlling air pollutants in Dhaka, Bangladesh. Atmospheric Environment 45(40): 7705-7713.

Begum, B.A., P.K. Hopke, A. Markwitz. 2013. Air pollution by fine particulate matter in Bangladesh. Atmospheric Pollution Research 4(1): 75-86.

Begum, B.A., Md. Nasiruddin, S. Randal, B. Sivertsen, and P. Hopke. 2014. Identification and apportionment of sources from air 
particulate matter at urban environments in Bangladesh. Current Journal of Applied Science and Technology 4(27): 3930-3955.

Begum, B.A., S.K. Paul, M. Dildar Hossain, S.K. Biswas, and P.K. Hopke. 2009. Indoor air pollution from particulate matter emissions in different households in rural areas of Bangladesh. Building and Environment 44(5): 898-903.

BGS (British Geological Survey) and DPHE (Department of Public Health Engineering). 2001. Arsenic contamination of groundwater in Bangladesh, Vol. 2. Final Report WC/00/19. Keyworth: British Geological Survey and Bangladesh Department of Public Health Engineering.

Bhattacharya, P., D. Polya, and D. Jovanovic. 2017. Best practice guide on the control of arsenic in drinking water. London: IWA Publishing.

Bhattacharjee, S., B. Saha, B. Saha, M. Sadid Uddin, C.H. Panna, P. Bhattachary, and R. Saha. 2019. Groundwater governance in Bangladesh: Established practices and recent trends. Groundwater for Sustainable Development 8: 69-81.

Birkmann, J., and P. Peduzzi. 2007. Measuring Vulnerability to Natural Hazards: towards disaster resilient societies. The Disaster Risk Index: Overview of a quantitative approach. New Delhi, India: The Energy and Resources Institute (TERI).

Bleich, S.N., T.L.P. Koehlmoos, M. Rashid, D.H. Peters, and G. Anderson. 2011. Noncommunicable chronic disease in Bangladesh: Overview of existing programs and priorities going forward. Health Policy 100(2-3): 282-289.

Brammer, H. 2009. Mitigation of arsenic contamination in irrigated paddy soils in South and South-east Asia. Environment International 35(6): 856-863.

Brammer, H., and P. Ravenscroft. 2009. Arsenic in groundwater: A threat to sustainable agriculture in South and South-east Asia. Environment International 35(3): 647-654.

Brodie, C. 2017. These are the world's most crowded cities. https:// www.weforum.org/agenda/2017/05/these-are-the-world-s-most crowded- cities/. Accessed 1 Jun 2018.

Cai, H., N.S.N. Lam, Y. Qiang L. Zou, R.M. Correl, and V. Mihunov. 2018. A synthesis of disaster resilience measurement methods and indices. International Journal of Disaster Risk Reduction 31: 844-855.

Carbonell-Barrachina, Á.A., A.J. Signes-Pastor, L. Vázquez-Araújo, F. Burló, and B. Sengupta. 2009. Presence of arsenic in agricultural products from arsenic-endemic areas and strategies to reduce arsenic intake in rural villages. Molecular Nutrition and Food Research 53(5): 531-541.

Chakraborti, D., M.M. Rahman, B. Das, M. Murrill, S. Dey, S. Chandra Mukherjee, R.K. Dhar, B.K. Biswas, et al. 2010. Status of groundwater arsenic contamination in Bangladesh: A 14-year study report. Water Research 44(19): 5789-5802.

Chakraborti, D., M.M. Rahman, A. Mukherjee, M. Alauddin, M. Hassan, R.N. Dutta, S. Pati, S.C. Mukherjee, et al. 2015. Groundwater arsenic contamination in Bangladesh-21 Years of research. Journal of Trace Elements in Medicine and Biology 31: 237-248.

Chaudhary, U.K., B.K. Biswas, T.R. Choudhury, G. Samanta, B.K. Mandal, G.C. Basu, C.R. Chanda, D. Lodh, et al. 2000. Ground water arsenic contamination in Bangladesh and West Bengal, India. Environmental Health Perspective 108(5): 393-397.

Chowdhury, M.A.I., M.T. Uddin, M.F. Ahmed, M.A. Ali, S.M.A. Rasul, M.A. Hoque, R. Alam, R. Sharmin, et al. 2006. Collapse of Socio-economic Base of Bangladesh by Arsenic Contamination in Groundwater. Pakistan Journal of Biological Sciences 9(9): 1617-1627.

Chowdhury, M.S.H., M. Koike, S. Akther, and Md.D. Miah. 2011. Biomass fuel use, burning technique and reasons for the denial of improved cooking stoves by Forest User Groups of Rema-
Kalenga Wildlife Sanctuary, Bangladesh. International Journal of Sustainable Development \& World Ecology 18(1): 88-97.

da Silva, J., S. Kernaghan, and A. Luque. 2012. A systems approach to meeting the challenges of urban climate change. International Journal of Urban Sustainable Development 4(2): 125-145.

Dittmar, J., A. Voegelin, L.C. Roberts, S.J. Hug, G.C. Saha, M.A. Ali, A.B.M. Badruzzaman, and R. Kretzschmar. 2007. Spatial distribution and temporal variability of arsenic in irrigated rice fields in Bangladesh. 2. Paddy soil. Environmental Science \& Technology 41(17): 5967-5972.

Eckstein, D., V. Künzel, and L. Schäfer. 2018. Global climate risk index 2018. Who suffers most from extreme weather events? Weather-related loss events in 2016 and 1997 to 2016. Briefing Paper. Think Tank \& Research; German Watch. https://german watch.org/sites/germanwatch.org/files/publication/20432.pdf. Accessed 18 Sept 2019.

Ellis, P., and M. Roberts. 2016. Leveraging urbanization in South Asia. Managing spatial transformation for prosperity and liveability. Washington, DC: World Bank.

Feroze Ahmed, M., and T. Ahmed. 2014. Status of remediation of arsenic contamination of groundwater. In Comprehensive water quality and purification, ed S. Ahuja, 104-121. Amsterdam: Elsevier.

GoB DoE (Government of Bangladesh Department of Environment). 2012. Air pollution reduction strategy for Bangladesh. Dhaka: Department of Environment, Government of Bangladesh.

Goel, V., M.S. Islam, M. Yunus, M.T. Ali, A.F. Khan, N. Alam, A.S.G. Faruque, G. Bell, et al. 2019. Deep tubewell microbial water quality and access in arsenic mitigation programs in rural Bangladesh. Science of the Total Environment 659: 1577-1584.

Gurley, E.S., H. Salje, N. Homaira, P.K. Ram, R. Haque, W.A. Petri, J. Bresee, W.J. Moss, et al. 2013. Seasonal concentrations and determinants of indoor particulate matter in a low-income community in Dhaka, Bangladesh. Environmental Research 121: $11-16$.

Guttikunda, S.K., B.A. Begum, and Z. Wadud. 2013. Particulate pollution from brick kiln clusters in the Greater Dhaka region, Bangladesh. Air Quality, Atmosphere \& Health 6(2): 357-365.

Hernantes, J., P. Maraña, R. Gimenez. J.M. Sarriegi, and L. Labaka. 2019. Towards resilient cities: A maturity model for operationalizing resilience. Cities 84: 96-103.

Hossain, M.S., F.A. Johnson, J.A. Dearing, and F. Eigenbrod. 2016. Recent trends of human wellbeing in the Bangladesh delta. Environmental Development 17: 21-32.

ICCCAD (International Centre for Climate Change and Development). 2014. What does the IPCC say about Bangladesh? Dhaka: ICCCAD. http://www.icccad.net/what-does-the-ipcc-report-sayabout-climate-change-in-bangladesh/. Accessed 18 Sept 2019.

Inauen, J., and H.-J. Mosler. 2014. Developing and testing theorybased and evidence-based interventions to promote switching to arsenic-safe wells in Bangladesh. Journal of Health Psychology 19(12): 1483-1498.

Islam, A., and T. Biswas. 2014. Chronic non-communicable diseases and the healthcare system in Bangladesh: Current status and way forward. Chronic Disease International 1(2): 1-6.

Islam, S.M.S. 2017. Human resources for non-communicable diseases in Bangladesh. International Journal of Perceptions in Public Health 1(2): 98-101.

Johnston, R., S.J. Hug, J. Inauen, N.I. Khan, H.-J. Mosler, and H. Yang. 2014. Enhancing arsenic mitigation in Bangladesh: Findings from institutional, psychological, and technical investigations. Science of the Total Environment 488-489: 477-483.

Junaid, M., J.H. Syed, N.A. Abbasi, M.Z. Hashmi, R.N. Malik, and D.S. Pei. 2018. Status of indoor air pollution (IAP) through particulate matter (PM) emissions and associated health concerns in South Asia. Chemosphere 191: 651-663. 
Kabir, Md.H., M. Sato, U. Habbiba, and T.B. Youuf. 2018. Assessment of urban disaster resilience in Dhaka North City Corporation (DNCC), Bangladesh. Procedia Engineering 212: $1107-1114$.

Kabir, M.E., S. Serrao-Neumann, P. Davey, and M. Hoaason. 2018. Drivers and temporality of internal migration in the context of slow-onset natural hazards: Insights from north-west rural Bangladesh. International Journal of Disaster Risk Reduction 31: 617-626.

Karar, Z.A., N. Alam, and P.K. Streatfield. 2009. Epidemiological transition in rural Bangladesh, 1986-2006. Global Health Action 2(1): Article 1904.

Kawser Ahmed, M., N. Shahhen, M. Saiful Islam, M. Habibullah-AlMamun, S. Islam, M. Monirul Islam, G.K. Kundu, and L. Bhattacharjee. 2016. A comprehensive assessment of arsenic in commonly consumed foodstuffs to evaluate the potential health risk in Bangladesh. Science of the Total Environment 544: $125-133$

Khan, A. 2013. Bangladesh-The most climate vulnerable country. End poverty South Asia. http://blogs.worldbank.org/endpovertyin southasia/bangladesh-most-climate-vulnerable-country. Accessed 31 May 2018.

Khan, A.H., S.B. Rasul, A.K.M. Munir, M. Habibuddowla, M. Alauddin, S.S. Newaz, and A. Hussam. 2000. Appraisal of a simple arsenic removal method for ground water of Bangladesh. Journal of Environmental Science and Health, Part A 35(7): 1021-1041.

Khan, N.I., R. Brouwer, and H. Yang. 2014. Household's willingness to pay for arsenic safe drinking water in Bangladesh. Journal of Environmental Management 143: 151-161.

Khan, N.I., and H. Yang. 2014. Arsenic mitigation in Bangladesh: An analysis of institutional stakeholders' opinions. Science of the Total Environment 488-489: 493-504.

Khan, K., E. Ahmed, P. Factor-Litvak, X. Liu, A.B. Siddique, G.A. Wasserman, V. Slavkovich, D. Levy, et al. 2015. Evaluation of an elementary school-based educational intervention for reducing arsenic exposure in Bangladesh. Environmental Health Perspectives 123(12): 1331-1336.

Khan, R., S. Konishi, C. Fook, S. Ng, M. Umezaki, A.F. Kabir, S. Tasmin, and C. Watanabe. 2019. Association between short-term exposure to fine particulate matter and daily emergency room visits at a cardiovascular hospital in Dhaka, Bangladesh. Science of the Total Environment 646: 1030-1036.

Krajick, K., and D. Funkhouser. 2015. Battling arsenic poisoning in southeast Asia. Columbia University Irving Medical Center. http://newsroom.cumc.columbia.edu/blog/2015/07/16/battlingarsenic-poisoning-insoutheast-asia/. Accessed 6 Aug 2018.

Krishna, B., K. Balakrishnan, A.R. Siddiqui, B.A. Begum, D. Bachani, and M. Brauer. 2017. Tackling the health burden of air pollution in South Asia. The BMJ 359: Article j5209.

Krzyzanowski, M, J.S. Apte, S.P. Bonjour, M. Brauer, A.J. Cohen, and A.M. Prüss-Ustun. 2014. Air pollution in the mega-cities. Current Environmental Health Reports 1(3): 185-191.

Luby, S.P., D. Biswas, E.S. Gurley, and I. Hossain. 2015. Why highly polluting methods are used to manufacture bricks in Bangladesh. Energy for Sustainable Development 28: 68-74.

Luqman, M., M.M. Javed, A. Yasar, J. Ahmad, and A. Khan. 2013. An overview of sustainable techniques used for arsenic removal from drinking water in rural areas of the Indo-Pak subcontinent. Soil Environment 32(2): 87-95.

Mahmood, S.A.I. 2011. Air pollution kills 15,000 Bangladeshis each year: The role of public administration and governments integrity. Journal of Public Administration and Policy Research 3(4): 129-140.

Miah, M.D., H. Al Rashid, and M.Y. Shin. 2009. Wood fuel use in the traditional cooking stoves in the rural floodplain areas of
Bangladesh: A socio-environmental perspective. Biomass Bioenergy 33(1): 70-78.

Mirelman, A.J., S. Rose, J.A. Khan, S. Ahmed, D.H. Peters, L.W. Niessen, and A.J. Trujillo. 2016. The relationship between noncommunicable disease occurrence and poverty-evidence from demographic surveillance in Matlab, Bangladesh. Health Policy and Planning 31(6): 785-792.

Mobarak, A.M., P. Dwivedi, R. Bailis, L. Hildemann, and G. Miller. 2012. Low demand for non-traditional cookstove technologies. Proceedings of the National Academy of Sciences 109(27): 10815-10820.

Moghim, S., and R.J. Garna. 2019. Countries' classification by environmental resilience. Journal of Environmental Management 230: 345-354.

Mukherjee, A., M. Kundu, B. Basu, B. Sinha, M. Chatterjee, M.D. Bairagya, U.K. Singh, and S. Sarkar. 2017. Arsenic load in rice ecosystem and its mitigation through deficit irrigation. Journal of Environmental Management 197: 89-95.

Murcott, S. 2012. Arsenic contamination in the world: An international sourcebook. London: IWA Publishing.

Nickson, R., J. McArthur, W. Burgess, K.M. Ahmed, P. Ravenscroft, and M. Rahman. 1998. Arsenic poisoning of Bangladesh groundwater. Nature 395(6700): 338-339.

NIPORT (National Institute of Population Research and Training), Mitra and Associates, and ICF International. 2016. Bangladesh demographic and health survey 2014. Dhaka, Bangladesh, and Rockville, MD: NIPORT, Mitra and Associates, and ICF International.

Pearshouse, R. 2016. Nepotism and neglect: The failing response to arsenic in the drinking water of Bangladesh's rural poor. New York: Human Rights Watch.

Polizzotto, M.L, E.M. Lineberger, A.R. Matteson, R.B. Neumann, A.B. Badruzzaman, and M. Ashraf Ali. 2013. Arsenic transport in irrigation water across rice-field soils in Bangladesh. Environmental Pollution 179: 210-217.

Quansah, R., S. Semple, C.A. Ochieng, S. Juvekar, F.A. Armah, I. Luginaah, and J. Emina. 2017. Effectiveness of interventions to reduce household air pollution and/or improve health in homes using solid fuel in low-and-middle income countries: A systematic review and meta-analysis. Environment International 103: 73-90.

Rahman, K.M., R. Rummana, S. Aziz, and B. Nishat. 2008. Urban pollution in Dhaka City: A tripartite qualitative model for alleviation and prevention. In Proceedings of the International Conference on Sustainable Urban Environmental Practices, 28-31 October 2008, Chiang Mai, Thailand.

Rahman, M.A., A. Rahman, M.Z.K. Khan, and A.M.N. Renzaho. 2018. Human health risks and socio-economic perspectives of arsenic exposure in Bangladesh: A scoping review. Ecotoxicology and Environmental Safety 150: 335-343.

Ravenscroft, P., H. Brammer, and K. Richards. 2009. Arsenic pollution: A global synthesis, 1st edn. Chichester, UK, and Malden, MA: Wiley-Blackwell.

Ray-Bennett, N.S., A. Collins, A. Bhuiya, R. Edgeworth, P. Nahar, and F. Alamgir. 2010. Exploring the meaning of health security for disaster resilience through people's perspectives in Bangladesh. Health \& Place 16(3): 581-589.

Sanchez, T.R., D. Levy, M.H. Shahriar, M.N. Uddin, A.B. Siddique, J.H. Graziano, A. Lomax-Luu, A. van Geen, and M.V. Gamble. 2016. Provision of well-water treatment units to 600 households in Bangladesh: A longitudinal analysis of urinary arsenic indicates fading utility. Science of the Total Environment 563-564: 131-137.

Sawada, Y., M. Mahmud, and N. Kitano (eds.). 2017. Economic and social development of Bangladesh: Miracle and challenges, $1 \mathrm{st}$ edn. Cham: Palgrave Macmillan. 
Senanayake, N., and A. Mukherji. 2014. Irrigating with arsenic contaminated groundwater in West Bengal and Bangladesh: A review of interventions for mitigating adverse health and crop outcomes. Agricultural Water Management 135: 90-99.

Shafiquzzaman, M., M.S. Azam, I. Mishima, and J. Nakajima. 2009. Technical and social evaluation of arsenic mitigation in rural Bangladesh. Journal of Health, Population and Nutrition 27(5): 674-683.

Shamsudduha, M., G. Joseph, S.S. Haque, M.R. Khan, A. Zahid, and K.M.U. Ahmed. 2019. Multi-hazard groundwater risks to the drinking water supply in Bangladesh. Challenges to achieving the sustainable development goals. Policy Research Working Paper 8922. World Bank Group Global Water Practice.

Sharma, A.K., J.C. Tjell, J.J. Sloth, and P.E. Holm. 2014. Review of arsenic contamination, exposure through water and food and low cost mitigation options for rural areas. Applied Geochemistry 41: $11-33$.

Shell Global. 2019. Compare cities. https://www.shell.com/energyand-innovation/the-energy-future/future-cities/compare-cities. html. Accessed 18 Sept 2019.

Smedley, P.L., and D.G. Kinniburgh. 2002. A Review of the source, behaviour and distribution of arsenic in natural waters. Applied Geochemistry 17(5): 517-568.

Smith, K. 2013. Environmental hazards: Assessing risk and reducing disaster, 6th edn. London and New York: Routledge.

Toufique, K.A., and A. Islam. 2014. Assessing risks from climate variability and change for disaster prone zones in Bangladesh. International Journal of Disaster Risk Reduction 10: 236-249.

UNDP (United Nations Development Programme). 2018. Human development report 2018 update. http://hdr.undp.org/en/coun tries/profiles/BGD. Accessed 18 Sept 2019.

UNICEF (United Nations International Children's Emergency Fund). 2011. Bangladesh national drinking water quality survey of 2009. New York and Dhaka: UNICEF and Bangladesh Bureau of Statistics.

UNICEF (United Nations International Children's Emergency Fund). 2013. Current Issues. Arsenic contamination in groundwater No. 2. New York: UNICEF.

UNICEF (United Nations International Children's Emergency Fund), WSP (Water and Sanitation Program), FAO (Food and Agriculture Organization), and WHO (World Health Organization). 2010. Towards an arsenic safe environment in Bangladesh. Executive summary. https://www.unicef.org/infobycountry/files/ Towards_an_arsenic_safe_environ_summary(english)_22Mar 2010.pdf. Accessed 18 Sept 2019.

Urmee, T., and S. Gyamfi. 2014. A review of improved Cookstove technologies and programs. Renewable and Sustainable Energy Reviews 33: 625-635.

Wasserman, G.A., X. Liu, F. Parvez, H. Ahsan, P. Factor-Litvak, J. Kline, A. van Geen, V. Slavkovich, et al. 2007. Water arsenic exposure and intellectual function in 6-year-old children in Araihazar, Bangladesh. Environmental Health Perspectives 115(2): 285-289.

WHO (World Health Organization). 2011. Evaluation of certain contaminants in food. Seventy-second report of the joint FOA/ WHO expert committee on food additives. WHO technical report series No. 959. Geneva: WHO.

WHO (World Health Organization) (ed.). 2014. WHO guidelines for indoor air quality: Household fuel combustion. Geneva: WHO.

WHO (World Health Organization). 2016. Ambient air pollution: A global assessment of exposure and burden of disease. Geneva: WHO.

WHO (World Health Organization). 2017a. Noncommunicable diseases progress monitor. Geneva: WHO.

WHO (World Health Organization). 2017b. Don't pollute my future. The impact of the environment on children's health. Geneva: WHO.

WHO (World Health Organization). 2018. Arsenic. https://www.who. int/news-room/fact-sheets/detail/arsenic. Accessed 18 Sept 2019.

World Bank. 2005. Towards a more effective operational response: Arsenic contamination of groundwater in South and East Asian Countries. Volume I, policy report. Washington, DC: World Bank.

World Bank. 2008. Implementation completion and results report (IDA-34040). On a learning and innovation loan in the amount of SDR 3.6 million (US\$ 4.71 million equivalent) to the Government of Bangladesh for an air quality management project. (No. ICR0000607). Washington, DC: World Bank.

World Bank and IHME (Institute for Health Metrics and Evaluation). 2016. The cost of air pollution. Strengthening the economic case for action. Washington, DC: World bank.

World Bank. 2017. Bangladesh and World Bank partner together to strengthen e-governance and improve Dhaka's air quality. Washington, DC: World Bank. http://www.worldbank.org/en/ news/press-release/2017/04/18/bangladesh-and-worldbank-partnertogether-to-strengthen-e-governance-and-improve-dhakas-air-qual ity. Accessed 12 Aug 2018.

World Bank. 2018. World Bank open data. Country profile Bangladesh. https://databank.worldbank.org/views/reports/report widget.aspx ?Report_Name=CountryProfile \&Id=b450fd57\&tbar= y\&dd=y\&inf=n\&zm=n\&country=BGD. Accessed 18 Sept 2019.

Zhao, F.-J., S.P. McGrath, and A.A. Meharg. 2010. Arsenic as a food chain contaminant: Mechanisms of plant uptake and metabolism and mitigation strategies. Annual Review of Plant Biology 61: $535-559$.

Zobel, C.W, and M. Baghersad. 2018. Analytically comparing disaster resilience across multiple dimensions. Socio-Economic Planning Sciences. https://doi.org/10.1016/j.seps.2018.12.005. 